\title{
In search of quality indicators for Down syndrome healthcare: a scoping review
}

Francine A. van den Driessen Mareeuw ${ }^{1,2}$, Mirjam I. Hollegien ${ }^{1,2,6}$, Antonia M. W. Coppus , $^{3,4}$

Diana M. J. Delnoij ${ }^{1,5}$ and Esther de Vries ${ }^{1,2^{*}}$ (1)

\begin{abstract}
Background: The medical care chain around Down syndrome (DS) is complex, with many multidisciplinary challenges. The current quality of care is unknown. Outcome-oriented quality indicators have the potential to improve medical practice and evaluate whether innovations are successful. This is particularly interesting for the evolving care for people with DS and intellectual disabilities (ID). The aim of this study was to identify existing indicators for medical DS care, by reviewing the literature.
\end{abstract}

Methods: We systematically searched six databases (PubMed, EMBASE, Web of Science, CINAHL, PsycINFO, Google Scholar) for studies concerning the development and implementation of quality indicators for DS and/or ID care, published until February $1^{\text {st }} 2015$. The scoping review method was used, including systematic data extraction and stakeholder consultation.

Results: We identified 13 studies concerning quality indicators for ID care that obtained data originating from questionnaires (patient/family/staff), medical files and/or national databases. We did not find any indicator sets specifically for DS care. Consulted stakeholders did not come up with additional indicator sets. Existing indicators for ID care predominantly focus on support services. Indicators in care for people with ID targeting medical care are scarce. Of the 70 indicators within the 13 indicator sets, 10\% are structure indicators, 34\% process, 32\% outcome and $24 \%$ mixed. Ten of the 13 sets include indicators on the WHO quality dimensions 'patient-centeredness', 'effectiveness' and 'efficiency' of care. 'Accessibility' is covered by nine sets, 'equitability' by six, and 'safety' by four. Most studies developed indicators in a multidisciplinary manner in a joint effort with all relevant stakeholders; some used focus groups to include people with ID.

Conclusion: To our knowledge, this is the first review that searched for studies on quality indicators in DS care. Hence, the study contributes to existing knowledge on DS care as well as on measuring quality of care. Future research should address the development of a compact set of quality indicators for the DS care chain as a whole. Indicators should preferably be patient-centred and outcome-oriented, including user perspectives, while developed in a multidisciplinary way to achieve successful implementation.

Keywords: Down syndrome, Intellectual disability, Quality of health care, Quality indicators, Quality measures, Integrated delivery of health care

\footnotetext{
* Correspondence: e.devries@tilburguniversity.edu

${ }^{1}$ Tranzo, Scientific Center for Care and Welfare, Faculty of Social and

Behavioural Sciences, Tilburg University, PO Box 90153 (T-329), 5000 LE

Tilburg, The Netherlands

2Department of Paediatrics, Jeroen Bosch Hospital, 's-Hertogenbosch, The

Netherlands

Full list of author information is available at the end of the article
}

(c) The Author(s). 2017 Open Access This article is distributed under the terms of the Creative Commons Attribution 4.0 International License (http://creativecommons.org/licenses/by/4.0/), which permits unrestricted use, distribution, and reproduction in any medium, provided you give appropriate credit to the original author(s) and the source, provide a link to the Creative Commons license, and indicate if changes were made. The Creative Commons Public Domain Dedication waiver (http://creativecommons.org/publicdomain/zero/1.0/) applies to the data made available in this article, unless otherwise stated. 


\section{Background}

Down syndrome (DS), or (partial) trisomy 21, is the most prevalent chromosomal anomaly among new-borns with intellectual disabilities. The overall prevalence throughout the world is about 10 per 10000 new-borns [1-3]. DS is associated with a broad variety of age-related medical problems, ranging from congenital heart disease to dementia to recurrent respiratory infections [1-3]. The care chain around a person with DS is challenging and complex, involving numerous professionals [3-5]. This requires coordination of care and adequate age- and service-related transitions [4, 5].

Initiatives arise to improve the DS care. Skotko et al. (2013) describe how a DS specialty clinic can identify and address many healthcare needs of children and adolescents with DS beyond the provision of primary care [6]. In the Netherlands, numerous paediatric outpatient clinics now organise such multidisciplinary team appointments, including a visit to the paediatrician, physiotherapist, ENT (earn-nose-throat)-specialist and others, all on the same day. For adults with DS in the Netherlands, healthcare is less organised, although some $18+$ teams are being set up [7]. Internationally, difficulties are identified in care transition (from paediatric to adult care) and in persistent use of paediatric care by DS adults [8]. An achievement towards higher quality care for DS has been the development of guidelines $[9,10]$. In general, health checks are increasingly developed in the care for people with intellectual disabilities (ID) $[11,12]$. However, the quality of existing initiatives and the extent to which healthcare professionals adhere to existing guidelines is unclear $[13,14]$. More insight is needed into the care that is delivered to people with DS, in terms of types of care, its quality and its effect on clinical outcomes [14]. Quality indicators (also known as quality measures $[15,16])$ can provide this insight. They have the potential to structure the development of multidisciplinary teams, improve clinical decisions and guide organisational reform [17]. This study aimed to review existing data on quality indicators for DS care, including both clinical and organisational aspects, and to identify existing indicator sets.

Evaluating quality of healthcare (by using indicators) starts with defining 'quality of healthcare'. About half a century ago (1966) Donabedian formulated the frequently used framework that distinguishes three healthcare components: structure, process and outcome [17]. Accordingly, the quality of each of these 'care components' can be measured by structure, process or outcome indicators. Structure indicators assess the availability of the right facilities, such as staff, supplies, policies and protocols, but also the financial basis, e.g. insurance [18]. Process indicators assess whether "good" medical care, according to current evidence/knowledge, has been applied [17]. Care processes are actions that take place between a patient and care provider, i.e. technical interventions (e.g. measuring blood pressure) or interpersonal interactions (e.g. doctor-patient communication) [19]. In practice, process indicators are often operationalized as adherence to guidelines, but they could also include general assumptions like access to and timeliness of services, and coordination and continuation of care. Outcomes are the consequences of delivered care and the actual results of healthcare interventions, also expressed as the five Ds: death, disease, discomfort, disability and dissatisfaction [20]. Contributions of healthcare to the patient's quality and length of life may also be qualified as outcomes of healthcare [21, 22]. Outcome indicators have the potential to evaluate care cycles as a whole instead of single processes by itself [23]. Traditionally, measurement instruments (such as indicator sets) for quality of healthcare contain all three types of indicators [24].

Next to these three types of healthcare components, several quality dimensions of healthcare are defined. The World Health Organisation (2006) defines six dimensions of quality of care, i.e. care being effective, efficient, accessible, patient-centred, equitable and safe [25]. When it comes to integrated care, other quality dimensions should be considered as well, such as continuity and adequate transitions between care organisations [26].

Additionally, quality of care can be assessed at different levels, e.g. at the level of single providers, departments, hospitals or at the level of care chains as a whole: the combined efforts of all care providers together [27]. In the end, it is this care chain that delivers the total package of care to the patient, resulting in the final outcome [23]. Addressing the care chain as a whole in quality evaluation is quite challenging, because so many organisations and people are involved [23].

In order to contribute to quality improvement, indicators measuring quality of healthcare should themselves be of good quality, e.g. evidence based, and they should measure what they are designed to measure. An instrument that can be used as a manual to develop indicators is the AIRE instrument (Appraisal of Indicators through Research and Evaluation) [27]. In addition, AIRE can be used as a checklist to appraise the quality of indicators [28].

This study aims to review existing quality indicators for the DS care chain (for both children and adults with DS). We focus on the following research question:

Which indicators are available to assess the clinical and organisational quality of medical DS healthcare?

More specifically:

1) Which indicator sets are available and which indicators do they contain? 
a. Which components and levels of care are covered by these indicators?

b. Of which type (structure, process or outcome) are these indicators?

2) What is the quality of these indicator sets?

a. Which dimensions of quality are covered by the sets?

b. How have the sets been developed and implemented?

c. What can be said about other quality aspects of the sets?

\section{Methods}

A scoping study was carried out to map available indicator sets of healthcare for people with DS. A scoping study (or scoping review) is a specific type of literature review that may be used to examine research activity in a certain field of study, assess the usefulness of conducting a full systematic review, summarise research findings, or identify gaps in literature [29, 30]. Scoping studies are often conducted when little research has been done on the topic studied and a specific research question cannot be formulated [30, 31]. In an attempt to ascertain rigorousness and transparency, Arksey and O'Mally (2005) constructed a framework for conducting scoping studies [29]. The framework consists of five stages: 1) identifying the research question; 2) identifying relevant studies (search strategy); 3) selecting the studies; 4) charting the data (data extraction); 5) collating, summarising and reporting the results; and 6) (optional) consultation of stakeholders, resulting in suggestions for additional references and views $[29,30]$. We followed these stages.

\section{Search strategy}

The databases of PubMed, EMBASE, Web of Science, CINAHL, PsycINFO and Google Scholar were systematically searched for articles published until February 1, 2015 (no starting date). These six databases were selected together with a librarian to cover a wide range of biomedical and psychological literature from the perspective of different healthcare professionals (physicians, psychologists and nurses). The first group of search terms consisted of synonyms for people with DS. The second group of search terms comprised outcomes to target quality indicators, including quality management, quality improvement and benchmarking. Since results for only DS(-synonyms) were very scarce, the first group of search terms was broadened by adding search terms for (synonyms for) people with intellectual disabilities (ID) (Table 1). Search strategies were similar for each database, except for Google Scholar, which required a more narrowly defined search, since the entry fields did not accept as many search terms as the entry fields of the other databases.
Table 1 Search strategy

\begin{tabular}{ll}
\hline Population: & Outcomes: \\
\hline 1 Intellectual Disability & 11 Quality Indicators, Health Care \\
2 Mentally Disabled Persons & 12 Quality Improvement \\
3 Developmental Disabilities & 13 Total Quality Management \\
4 Down Syndrome & 14 Benchmarking \\
5 Developmental disorder* & 15 Clinical indicator* \\
6 Mental deficien* & 16 Quality measure* \\
7 Mental retard* & 17 Quality assessment* \\
8 Down's syndrome & 18 (11 OR 12 OR 13 OR 14 OR 15 \\
9 Trisomy 21 & OR 16 OR 17) (Google Scholar: \\
10 (1 OR 2 OR 3 OR 4 OR 5 & 11 OR 16) \\
OR 6 OR 7 OR 8 OR 9) & \\
(Google Scholar: 1 OR 2 & \\
OR 3 OR 4 OR 5 OR 6 OR 7) & \\
19 (NOT) Pregnancy & \\
\hline
\end{tabular}

Combining search term groups: 10 AND 18 NOT 19

This strategy is related to the PubMed search. Very similar versions were used to search EMBASE, Web of Science, CINAHL, PsycINFO and Google Scholar, but adapted for the specific search terms used in these databases, if available. The search terms printed in italics are not MeSH-terms. All MeSH Terms were also searched as free text in all databases as title/abstract

\section{Study selection}

Figure 1 shows the selection process in a flowchart. Specific inclusion and exclusion criteria are listed in Table 2. In the first selection phase, duplicates were removed, and two independent reviewers (MH or FDM, and EV) screened all titles. Titles were included in the next selection phase when they concerned quality aspects of healthcare for chronic conditions (comparable to DS care). This review focuses on the care chain for individuals with DS (or ID) from birth to end-of-life. Therefore, we excluded articles concerning prenatal screening. In the next selection phase, abstracts were screened based on more narrow criteria: focus on the development, implementation, application or evaluation of indicators for measuring quality of healthcare. $\mathrm{MH}$ and FDM selected all abstracts (partly by MH, partly by FDM) and a random selection of $30 \%$ of all abstracts was screened by a second reviewer (EV, DD, AC, each 10\%), which resulted in $26 \%$ differences in interpretation. For instance, one abstract mentioned 'Quality deficiencies'; FDM concluded from this that the study was not about indicators, whereas DD thought quality deficiencies could be another word for quality indicators: the study was selected. Another study was not selected, because AC doubted about inclusion and FDM interpreted that the study was not about indicators for healthcare. Discussion between the reviewers resolved all differences, which resulted in 100\% agreement about inor exclusion. MH and FDM reviewed full texts (partly by $\mathrm{MH}$, partly by FDM). In case of any doubt, EV also reviewed the articles and a third and fourth reviewer (DD and $\mathrm{AC}$ ) was consulted in case of disagreement. In this final phase, quality indicators had to be the main topic, well defined (as well as the population they applied to) and more specifically concerning medical healthcare, as opposed to e.g. residential care. A snowball method was 


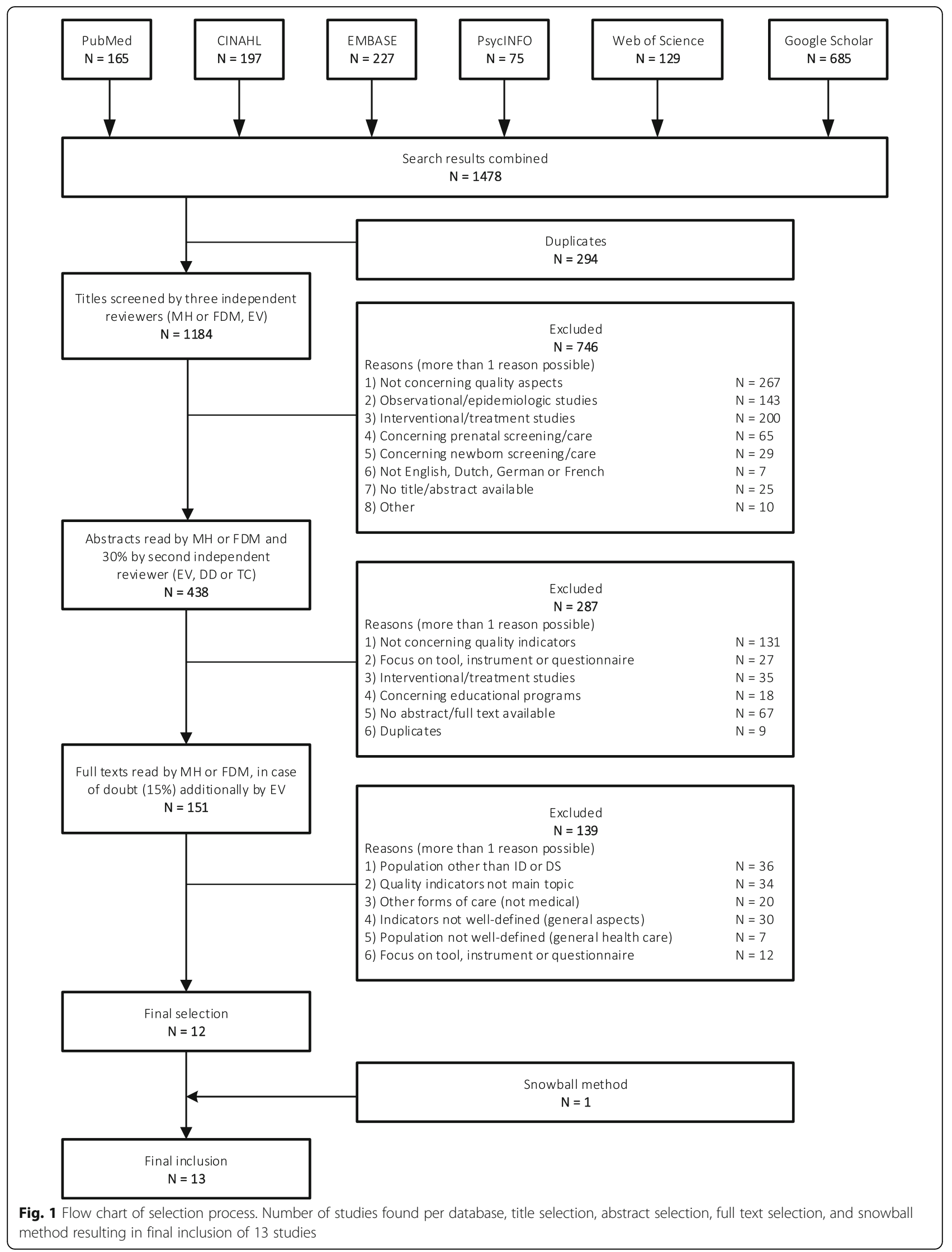


Table 2 Inclusion and exclusion criteria

Inclusion criteria:

- Studies concerning the development, implementation, application or evaluation of (structure, process or outcome) indicators for measuring quality of (chronic) medical healthcare for people with Down syndrome or intellectual disabilities as the main topic

- Studies where specific quality indicators are well-defined including the population they apply to

- All kinds of scientific publications: journal articles, theses, books, etc.

Exclusion criteria:

- Studies where quality indicators itself are not the main topic

- Studies not concerning medical care, but other forms of care (e.g. residential care)

- Studies concerning general aspects of quality indicators (specific indicators are not well-defined)

- Studies concerning quality indicators of general healthcare (specific population is not described)

- Studies primarily focusing on the development of a tool, instrument or questionnaire without the purpose of being an indicator for measuring quality of healthcare

- Studies concerning prenatal or new-born screening/care

- No abstract/full text available

- Written in a language that no one in the research team masters (i.e. not English, Dutch, French, German)

applied in order to find additional studies: Reference lists of the selected studies were screened for additional relevant studies. If titles mentioned in the reference lists suggested relevant information (on development, implementation or evaluation of indicators), these studies were retrieved and, based on full texts, FDM assessed whether the studies provided additional information. If the studies provided information about additional indicator sets and matched inclusion criteria, these studies were included. If snowball-studies in turn mentioned additional indicator sets in the text, corresponding references were searched too and included if relevant (this happened once).

\section{Data extraction}

As the included studies did not always provide enough information to be able to answer our research questions, additional information about the indicator sets was sought. This was done by looking on websites of the organisations who developed the indicator sets and by entering the name of the indicator set in Google and Google scholar.

We extracted data concerning general information about the indicator sets (name of indicator set, author, year, country, target population and organisational context) and about quality domains covered. With the additional information, we were able to assess the indicators in the sets in terms of type (structure, process, or outcome) and quality using the AIRE instrument (mentioned previously). Two researchers (FDM plus EV, DD or AC) appraised each indicator set. The AIRE instrument results in a score for each of its four categories: 1) Aim, relevance and organisational context; 2) Involvement of stakeholders; 3) Scientific evidence; and 4) Further underpinning, formulation and use. For each category, the reviewers need to score several items on a 4-point Likert-scale: 1 meaning not at all agree and 4 meaning very much agree. If no information was available about an item, this was scored as 1 . Table 3 provides an overview of the four categories of the instrument and of the items per category.

One researcher (FDM) assessed the type of the indicators, as the definition of the types was clear and all indicators could be easily attributed to one of the three types. Some indicators were very broadly defined and were therefore classified as 'mixed', covering information about two or more of the types. For each set, the percentages of the indicator types were calculated, after which the percentages per type were added up in order to provide an idea of relative distribution of indicator types for all the indicators in the sets.

\section{Consultation exercise}

Twenty representatives from the healthcare perspective (professionals providing different sorts of healthcare to people with DS in the Netherlands) and three from the healthcare receivers (board members of a leading Down syndrome association in the Netherlands) were asked (by e-mail) to review the list of selected studies and check whether they missed studies or indicator sets. We

Table 3 AIRE instrument categories and items per category [27]

\begin{tabular}{|c|c|}
\hline Categories & Items \\
\hline $\begin{array}{l}\text { 1) Aim, relevance and } \\
\text { organisational context }\end{array}$ & $\begin{array}{l}\text { - Aim is clearly defined, } \\
\text { - Topic relevance is specified, } \\
\text { - Organisational configuration (level) is } \\
\text { specified, } \\
\text { - Quality domain is specified, } \\
\text { - Type and size of care process the indicator } \\
\text { set applies to is defined. }\end{array}$ \\
\hline $\begin{array}{l}\text { 2) Involvement of } \\
\text { stakeholders }\end{array}$ & $\begin{array}{l}\text { - Relevant healthcare professionals are } \\
\text { involved in developing the set, } \\
\text { - Relevant other are involved, } \\
\text { - The indicator set is formally established } \\
\text { (or owned), e.g. by a patient or professional } \\
\text { association. }\end{array}$ \\
\hline 3) Scientific evidence & $\begin{array}{l}\text { - Underpinning evidence for the set is } \\
\text { systematically searched, } \\
\text { - The set is based on a guideline, } \\
\text { - The Used evidence is qualitatively good. }\end{array}$ \\
\hline $\begin{array}{l}\text { 4) Further underpinning, } \\
\text { formulation and use }\end{array}$ & $\begin{array}{l}\text { - Denominator and numerator are clearly } \\
\text { described, } \\
\text { - Target population is specifically and clearly } \\
\text { defined, } \\
\text { - A risk adjustment strategy (for different } \\
\text { patient groups) is present, } \\
\text { - Validity of the set is proven or argued, } \\
\text { - Reliability of the set is proven or argued, } \\
\text { - Power of the set is proven or argued, } \\
\text { - The set is tested in practice, } \\
\text { - The effort needed for data collection is } \\
\text { taken into account, } \\
\text { - The set includes an instruction for } \\
\text { interpretation of the results. }\end{array}$ \\
\hline
\end{tabular}


also asked them about their opinions concerning indicator sets for DS care in general. Four representatives (from the professionals group) did not review the identified studies and indicator sets because of time constraints and/or lack of interest in the topic.

\section{Results}

The literature search yielded 1184 studies (see Fig. 1). No studies specific for DS care were found. Thirteen studies were selected for final inclusion: they contained quality indicators for medical healthcare in people with ID (see Table 5, second column). Consultation of stakeholders did not result in additional studies or indicator sets. All stakeholders agreed that developing indicators for medical care for people with DS would be worthwhile for improving quality or transparency (see Table 4).

\section{Research question 1: Which indicator sets are available and which indicators do they contain?}

Thirteen different indicator sets were identified (Table 5), five of which originate from the UK, four from the USA, one from Canada, one from Ireland, one from Sweden, and one as a result of a partnership between 13 European countries.

Out of the 13 identified indicator sets, three have not been specifically developed for people with ID. The three studies describing these sets only evaluated existing indicators in people with ID, by comparison with the general population (no. 9, Quality indicators for preventive care; no. 3, Healthcare Effectiveness Data and Information Set; no. 10, Quality care indicators of diabetes for people with ID). Others adjusted existing sets of indicators to apply them in care for people with ID (no. 1, Ambulatory Care Sensitive Conditions; no. 2, Hospital Admissions for Ambulatory Care Sensitive Conditions; no.5, Measurement of Processes of Care; no. 11, Six Core Outcomes). Three indicator sets have been developed or used for children with, or at risk for, ID, i.e. no. 5 (MPOC-28), no. 9 (Quality indicators for preventive care), and no. 11 (Six

Table 4 Answers of stakeholders

Number of times mentioned by stakeholders $(N=19)$

\begin{tabular}{lc}
\hline Why are indicators for DS relevant? & 8 \\
To define care & 7 \\
For coordination & 8 \\
For quality improvement & 14 \\
For comparability of care providers & 3 \\
To check availability & \\
Additional studies? & 11 \\
No & 8 \\
Yes but not about indicators & \\
\hline
\end{tabular}

core outcomes). An overview of the indicators per set, including their content, can be found as Additional file 1 to this article.

\section{Research question 1a: Which components and levels of care are covered by the indicators?}

The indicator sets cover a large variety of healthcare levels (settings) and topics. The sets predominantly evaluate the presence of facilities/services or the effectuation of care delivery at communicational and organisational levels. Most of the sets include indicators on collaboration, multidisciplinary cooperation, transition and coordination. Five of the identified sets focus on quality of supportive care and services, containing only a subcategory of indicators being applicable to medical care: no. 3 (The Health Equalities Framework, HEF), no. 6 (National Core Indicators, NCI), no. 7 (the NHS quality indicators for Learning Disabilities, NHS-QIS), no. 9 (the Quality indicators for preventive care), and no. 11 (the Six Core Outcomes). Medical care is approached in a general way and specific diseases and/or treatment courses are barely addressed. Indicators on medical topics primarily focus on screening and preventive care. Two sets consider hospitalisation rates as indicators for conditions which, given effective primary care, should not normally result in hospital admission. Their indicators aim to measure access to, and quality of, primary care: no. 1 (Ambulatory Care Sensitive Conditions) and no. 2 (Hospital Admissions for Ambulatory Care Sensitive Conditions). One set, no. 12 (Quality Outcomes Framework, QOF) contains - among others - an indicator named 'Learning disabilities', which comprises a measure for a register of patients with learning disabilities and a measure for thyroid disease among people with DS. This is the only set explicitly addressing DS. The QOF indicators have been designed to measure the quality of primary care in Great Britain. Two indicator sets include measures for diabetes care for people with intellectual disabilities (no. 3, Healthcare Effectiveness Data and Information Set; no. 10, Quality care indicators of diabetes for people with ID). Lastly, two sets focus on processes of care: i.e. no. 5 (MPOC-28) concerning processes in child rehabilitation and no. 13 (Quality indicators for medication use process) including indicators for medication use in people with ID.

\section{Research question 1b: Of which type (structure, process and outcome) are the indicators?}

The number of indicators per set varies widely. The thirteen sets together comprise 70 separate indicators, ranging from 2 to 6 indicators per set. Most indicators in turn consist of a number of sub-indicators ranging from 14 to 94 . Altogether (regardless of sub-indicators) we identified 6 structure, 21 process, 26 outcome indicators, 


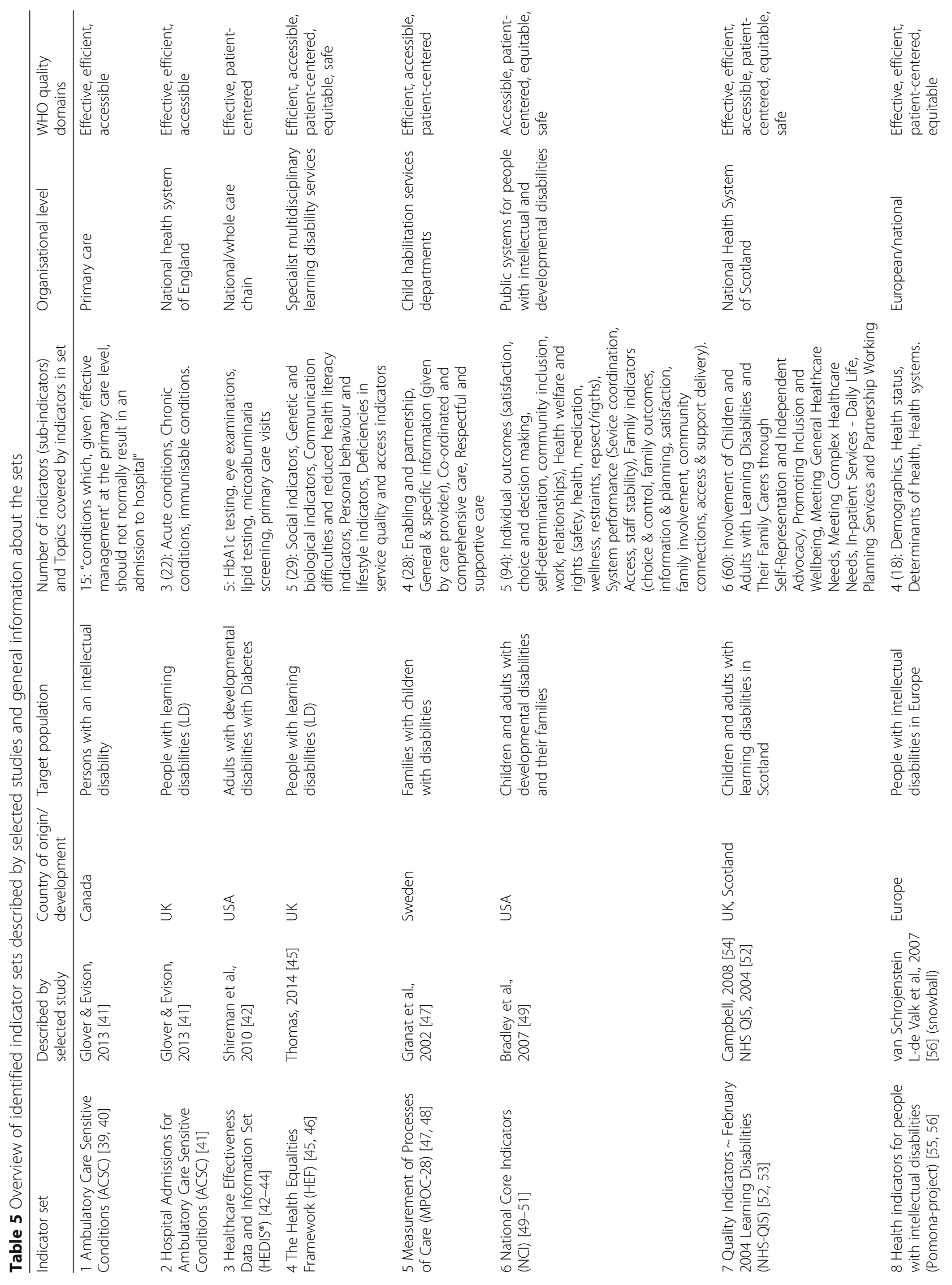




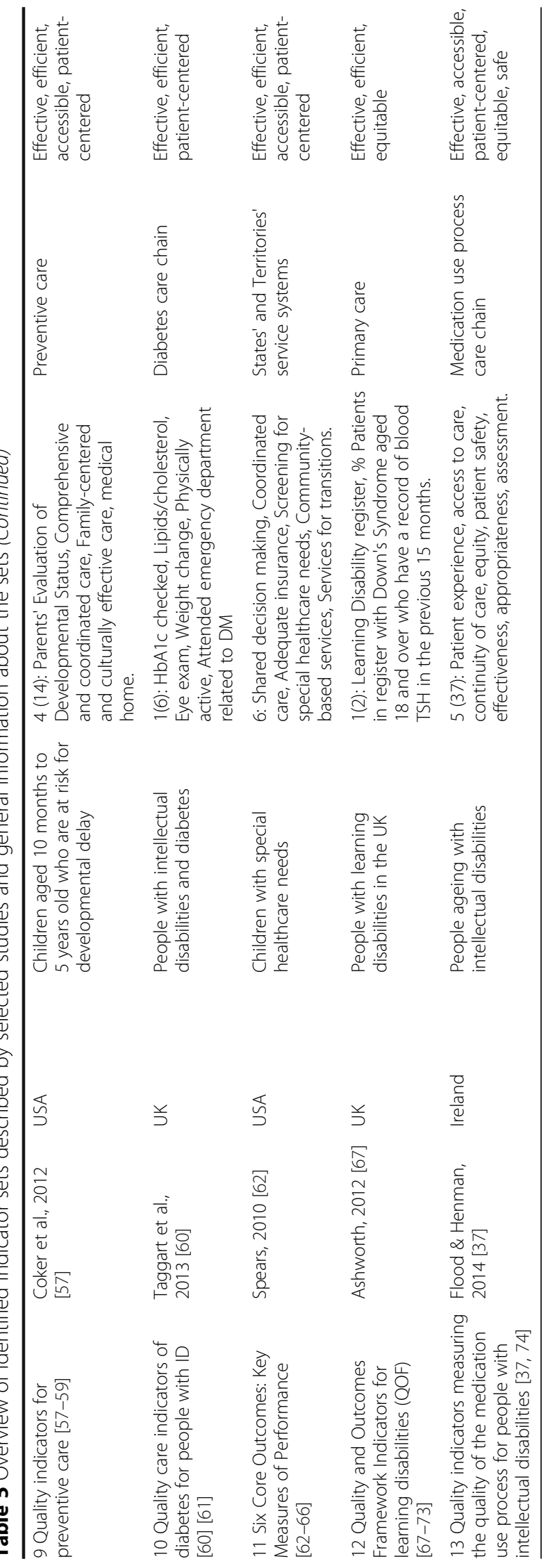


and 12 indicators measuring a mix of structure-, process-, or outcome-measures. When calculating the percentages of types of indicators per sets, and then adding up the percentages per type, it appeared that $10 \%$ of the 70 indicators are structure indicators, 34\% process, $32 \%$ outcome and $24 \%$ mixed. Table 6 presents the distribution of the types of indicators per set.

\section{Research question 2: What is the quality of the indicator sets?}

The quality of the indicator sets was assessed using the AIRE instrument. The AIRE-scores are presented in Fig. 2.

Although category 1 did not get the highest score in all sets (sets 1, 7, 8, 9, and 11 got a higher score on category 2 and set 5 on category 3), category 1 is the best scoring category on average. All sets have clearly defined the aim and relevance and specify the organisational configuration, type of care, quality dimension on which the indicators apply, and indicate the relevance of the topic. All WHO quality dimensions (effective, efficient, accessible, patient-centred, equitable and safe) are covered (Table 7), although some dimensions are only covered by a small number of sets (e.g. only four indicator sets cover 'safety'). The domains 'effective', 'efficient', and 'patientcentred' are covered by ten of the sets. This implies that a

Table 6 Relative and absolute proportion of types of indicators in identified indicator sets

\begin{tabular}{lllll}
\hline $\begin{array}{l}\text { Type of indicator } \rightarrow \\
\text { Indicator sets } \downarrow\end{array}$ & Structure & Process & Outcome & Mix \\
\hline 1 ACSC CAN & 0 & 0 & $100 \%(15)$ & 0 \\
2 ACSC UK & 0 & 0 & $100 \%(3)$ & 0 \\
3 HEDIS DM & 0 & $100 \%(5)$ & 0 & 0 \\
4 HEF & 0 & $40 \%(2)$ & $20 \%(1)$ & $40 \%(2)^{a}$ \\
5 MPOC-28 & 0 & $100 \%(4)$ & 0 & 0 \\
6 NCl & $20 \%(1)$ & $20 \%(1)$ & $20 \%(1)$ & $40 \%(2)^{b}$ \\
7 NHS-QIS & $33 \%(2)$ & $17 \%(1)$ & 0 & $50 \%(3)^{c}$ \\
8 POMONA & 0 & 0 & $75 \%(3)$ & $25 \%(1)^{d}$ \\
9 Preventive care & 0 & $75 \%(3)$ & $25 \%(1)$ & 0 \\
10 Diabetes UK & 0 & 0 & 0 & $100 \%(1)^{\mathrm{e}}$ \\
11 Six core outcomes & $33 \%(2)$ & $67 \%(4)$ & 0 & 0 \\
12 QOF & $50 \%(1)$ & 0 & $50 \%(1)$ & 0 \\
13 Medication use process & 0 & $20 \%(1)$ & $20 \%(1)$ & $60 \%(3)^{\mathrm{f}}$ \\
Total & $86(6)$ & $439(21)$ & $420(26)$ & $315(12)$ \\
\hline
\end{tabular}

${ }^{a}$ Mixed indicators consist of a mix of 1) structure \& outcome sub-indicators and 2) structure \& process sub-indicators

${ }^{\mathrm{b}}$ Mixed indicators consist of a mix of 1) structure \& process \& outcome subindicators and 2) structure \& process sub-indicators

${ }^{c}$ Mixed indicator consist of a mix of structure \& process sub-indicators

${ }^{\mathrm{d}}$ Mixed indicator consist of a mix of structure \& process sub-indicators

Mixed indicator consist of a mix of process \& outcome sub-indicators

${ }^{f}$ Mixed indicators consist of a mix of 1 ) process \& outcome sub-indicators ( $2 x$ ) and 2) process \& outcome \& structure sub-indicators large part of the indicator sets aim to measure (and improve) these dimensions of care. 'Accessibility' is covered by nine sets, 'equitability' by six, and 'safety' by four.

In general, there are differences in whether relevant stakeholders have been involved in developing the sets (AIRE-category 2). In most studies, indicators have been developed in a multidisciplinary manner with involvement of the relevant stakeholders. These stakeholders involve general practitioners, paediatricians, psychologists, social workers, direct care staff, researchers, policy makers, managers and/or family members. In most cases, the actual content of the multidisciplinary team is not clearly described. Two studies have been using focus groups to include people with ID in the development process (Atkinson et al. 2013, van Schrojenstein Lantman-de Valk et al. 2007). Other ways of obtaining data for the development of indicators include Delphi studies, web-based applications, on-site observations, staff questionnaires, medical file recordings, financial registrations, content of protocols and/or national databases.

The evidence base of the sets, category 3, provided the lowest scores, though some sets score quite high (no. 1, $3,4,5$ and 8).

Finally, category 4 (Further underpinning, formulation and use) covers a large variety of indicator characteristics (see Table 3) and the score for this category differs between the sets. Some of the sets do not contain indicators with a numerator and denominator, e.g. the two sets on diabetes care contain the indicator 'patient's HbA1c is checked'. Furthermore, some sets clearly report how validity and reliability have been assured, while others do not contain any information on that. The same is true for the power of the sets (the extent to which an indicator is sensible to measure changes). Almost all sets have to some extent been implemented and tested in practice. However, some sets have only been implemented and tested once, while others have been in use for many years. Data collection of the indicator sets also varied. For three of the sets, data collection methods are not (yet) specified (sets 1, 4 and 13). Six of the sets (sets 5, 6, 8, 9, 10, and 11) collect data through telephone surveys, postal questionnaires or face-to-face interviews with people with ID or their representatives. Three sets use existing registrations for obtaining data $(2,3$, and 7$)$. For one set (12), general practices have to score points on several topics, it is unclear whether this is done through a questionnaire or existing registrations.

\section{Discussion}

\section{Summary of results}

We reviewed the literature to identify indicators that assess the clinical and organisational quality of medical 


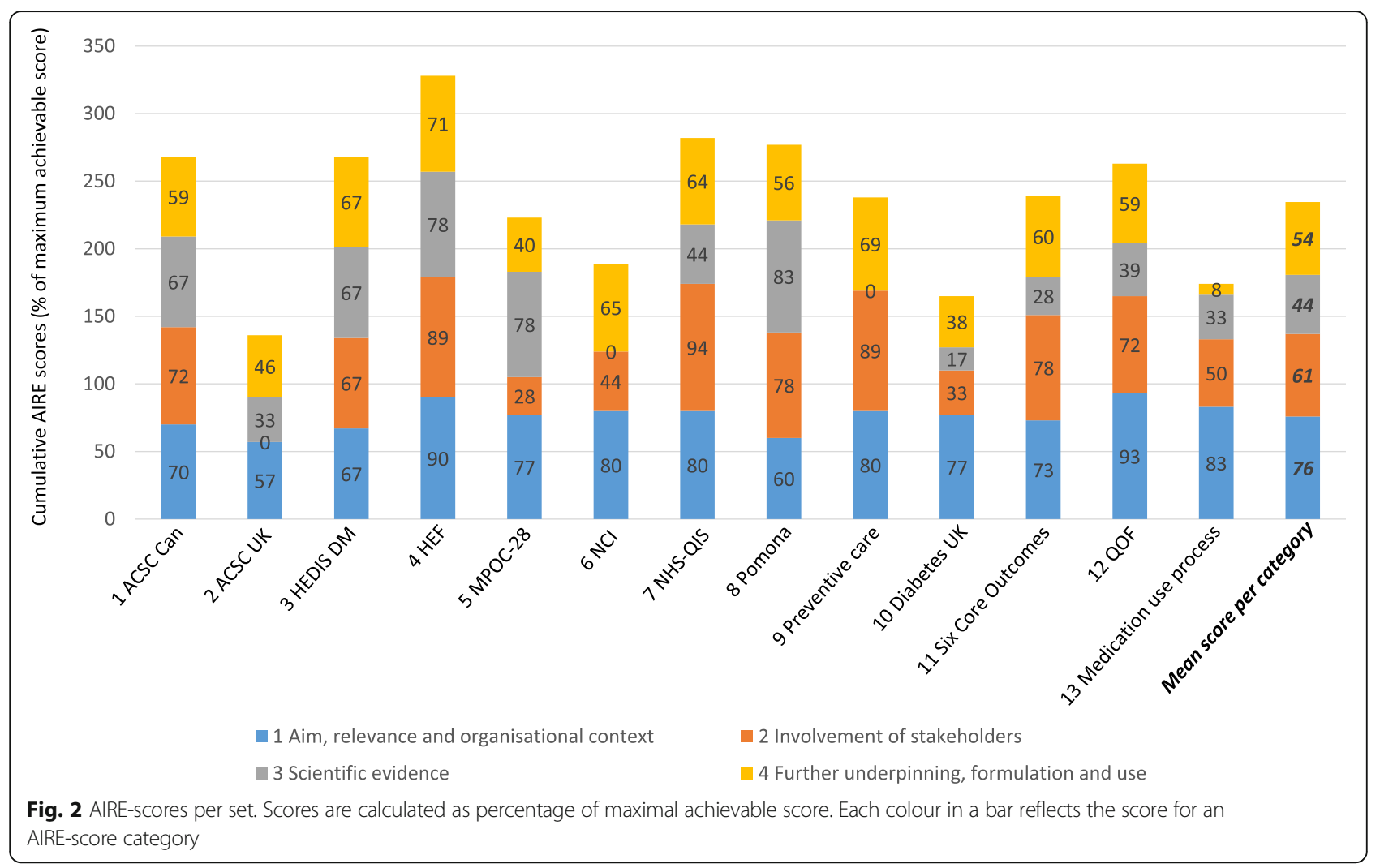

care for people with DS. Only one of the found studies described an indicator set containing one single indicator on thyroid disease among people with DS; the other studies were not about DS care. Therefore, we have chosen to search for quality indicators in care for people with ID that could be applicable in DS care. We have found that quality indicators in care for people with ID targeting medical care, instead of supportive care and services, were scarce. We reviewed to what extent these indicators cover the structure, process and outcome of care. The majority of indicators concern processes of care for performance measurement. Many sets include

Table 7 Quality dimensions covered by indicator sets, per dimension

\begin{tabular}{|c|c|c|c|c|c|c|}
\hline $\begin{array}{l}\text { Quality dimension } \rightarrow \\
\text { Indicator sets } \downarrow\end{array}$ & Effective & Efficient & Accessible & Patient-centered & Equitable & Safe \\
\hline 1 ACSC CAN & $\sqrt{ }$ & $\sqrt{ }$ & $\sqrt{ }$ & & & \\
\hline 2 ACSC UK & $\sqrt{ }$ & $\sqrt{ }$ & $\sqrt{ }$ & & & \\
\hline 3 HEDIS DM & $\sqrt{ }$ & & & $\sqrt{ }$ & & \\
\hline $4 \mathrm{HEF}$ & & $\sqrt{ }$ & $\sqrt{ }$ & $\sqrt{ }$ & $\sqrt{ }$ & $\sqrt{ }$ \\
\hline 5 MPOC-28 & & $\sqrt{ }$ & $\sqrt{ }$ & $\sqrt{ }$ & & \\
\hline $6 \mathrm{NCl}$ & & & $\sqrt{ }$ & $\sqrt{ }$ & $\sqrt{ }$ & $\sqrt{ }$ \\
\hline $7 \mathrm{NHS}-\mathrm{QIS}$ & $\sqrt{ }$ & $\sqrt{ }$ & $\sqrt{ }$ & $\sqrt{ }$ & $\sqrt{ }$ & $\sqrt{ }$ \\
\hline 8 POMONA & $\sqrt{ }$ & $\sqrt{ }$ & & $\sqrt{ }$ & $\sqrt{ }$ & \\
\hline 9 Preventive care & $\sqrt{ }$ & $\sqrt{ }$ & $\sqrt{ }$ & $\sqrt{ }$ & & \\
\hline 10 Diabetes UK & $\sqrt{ }$ & $\sqrt{ }$ & & $\sqrt{ }$ & & \\
\hline 11 Six core outcomes & $\sqrt{ }$ & $\sqrt{ }$ & $\sqrt{ }$ & $\sqrt{ }$ & & \\
\hline 12 QOF & $\sqrt{ }$ & $\sqrt{ }$ & & & $\sqrt{ }$ & \\
\hline 13 Medication use process & $\sqrt{ }$ & & $\sqrt{ }$ & $\sqrt{ }$ & $\sqrt{ }$ & $\sqrt{ }$ \\
\hline Number of sets covering dimension & 10 & 10 & 9 & 10 & 6 & 4 \\
\hline
\end{tabular}


indicators on coordination, multidisciplinary working and cooperation. The six WHO quality dimensions are well covered by the sets, although 'safety' is the least addressed. We also aimed to evaluate the development and implementation of the indicators. Most quality indicators have been developed in a multidisciplinary manner with relevant stakeholders, some using focus groups to include people with ID. Almost all sets have to some extent been implemented and tested in practice. Data collection for the indicators is achieved in multiple ways, such as consumer/family surveys, medical file recordings, and/or national databases. The sets differ in quality aspects, e.g. some authors describe thoroughly how validity and reliability was assured, how sensible the indicators are and what the evidence base is, while others barely address these issues.

\section{Quality indicators in medical care for people with ID and DS}

The most striking finding of the current study is that quality indicators specific for DS care have not been published to date (except for the single set containing one indicator on thyroid disease among people with DS). Moreover, the indicators found for the care for people with ID barely address medical aspects. Generally, people with DS and people with ID have similar health needs [4], which may imply that the identified quality indicators would be applicable in DS care as well. However, people with DS usually have more and many specific comorbidities compared to the general population of people with ID [4]. This urges the need for both medical care that is specifically tailored to the healthcare needs of people with DS and DS specific indicators, which can contribute to the quality of life of people with DS [6]. Indicators for care for people with ID would not be specific enough. DS specific indicators can reveal bottlenecks in the care chain and can lead to the identification of successful interventions and contributors to a specific outcome [23].

The high prevalence of comorbidities among people with DS also requires multidisciplinary collaboration and coordination. Many of the indicator sets found in this study contain indicators for these requirements. They are general concepts that are applicable to different healthcare sectors, regardless of the patient group. Thus, regarding multidisciplinary collaboration and coordination, the identified indicators could be used in a set for healthcare for people with DS.

The six WHO quality dimensions could also be used to define potential indicators [25]. In this study we found that the dimensions 'effective', 'efficient', and 'patientcentred' are predominantly covered (ten out of thirteen), while improvement of care - addressing total care chains - should always be done by paying attention to all the six dimensions [25]. Nonetheless, we believe that 'equitability' and 'patient-centeredness' should receive special attention in DS. People with DS experience inequality in received healthcare [32]. The comorbidities, communication difficulties caused by intellectual disability, and unusual presentation of common diseases of people with DS require more effort from healthcare professionals to deliver good care [6].

\section{Structure, process or outcome of care}

Of the indicator sets we found in this study, many consist of a large number of process indicators. Outcome indicators also comprise a significant part (although less than process) of the indicators in the sets. The number of structure indicators is the lowest.

Many organisations focus on the assessment of structural aspects and service delivery for performance measurement. They seem to assess results that are easy to reach and easy to measure, with data readily collectable $[19,23,33,34]$. Structural aspects of care are essential, as they are the basis of the healthcare system. Structure indicators are based on the assumption that given the presence of right physical or staff characteristics, good care automatically results [17]. However, focusing merely on the structural context as an end in itself, may result in overshadowing the initial goal of improving health outcomes for patients [33].

Process indicators are based on how healthcare is delivered, e.g. coordination, timeliness, interactions, and what interventions take place, e.g. screening or diagnostic tests, treatment etc. Measuring processes has several benefits: they can be measured on a short-term (i.e. directly after care has been delivered), data are easily obtained and differences between organisations are relatively easy to interpret. In general, process indicators are largely based on (the adherence to) guidelines, consisting of recommendations based on current evidence, or best knowledge. Measuring the adherence to guidelines results in important information on the feasibility of recommended care and to some extent, information on care quality. However, standards of best clinical practice are not stable and almost never final [17]. When we solely measure processes we might risk anchoring what is currently known as best practice, which might result in ceasing of innovation [23].

Outcome indicators measure the consequences of delivered care and actual results of healthcare interventions. They reflect whether structural context and processes in single organisations, as well as total care chains [20], actually lead to health benefits. This information on desired, as well as detrimental outcomes may stimulate innovation through the identification of its contributing factors [23]. Outcomes can therefore be interpreted as fundamental measures for quality of healthcare. 


\section{Developing an indicator set for DS}

According to the above, development of indicators for medical care should focus on developing outcome indicators. There are however some considerations that should be taken into account. Firstly, stakeholders may have different views on which outcomes are desirable. Whereas survival may be the best scenario in the eyes of a physician, a patient may choose functional status above life expectancy. In addition, change in health-status may not always be the primary goal, especially in long-term care [26], support and processes of care may be of greater importance. Indeed, when evaluating user perspectives on this topic, users primarily seem to focus on processes of care or procedural outputs $[24,26]$. As patients are the experts when it comes to their outcomes, it is essential to include people with DS and/or their parents in the process to define what is valuable to them [35]. Their views on quality differ from those of professionals and researchers [26]. Physicians and all other professionals, including healthcare managers, should also be involved, since they might appraise the usefulness and quality of indicators in a different manner [36]. By involving all stakeholders in the development process their conflicting interests can be identified and weighed against each other. We also saw this stakeholder involvement in the development of many of the identified indicator sets. Defining potential quality indicators for DS should thus involve all relevant stakeholders [27, 37] (e.g. general practitioners, paediatricians, psychologists, social workers, direct care staff, researchers, policy makers, managers and family members).

Secondly, another consideration when developing outcome indicators is that before outcomes become manifest, long periods of time may elapse and data will not be readily available $[17,19,23]$. Therefore, long-term measures should be accompanied with intermediate, short-term outcomes [20].

Thirdly, as stated before, multidisciplinary working is of vital importance in medical care for people with DS. Moreover, Callaghan (2006) argues that, especially for people with ID, multidisciplinary collaboration leads to better personal outcomes [38]. This would be a reason for including process indicators, since multidisciplinary working is a typical process aspect of care. On the other hand, as multidisciplinary working leads to personal outcomes, outcome indicators may also be suitable to measure quality of care. In any case, multidisciplinary collaboration should be taken into consideration, whether it is measured by process or outcome indicators.

Fourthly, patient characteristics and environmental factors, e.g. intrinsic motivation or socio-economic status, have an important role in influencing health outcomes as well, beyond the control of individual health professionals [19], not to mention comorbidity. Hence, adjusting for this kind of factors outside the healthcare system that may influence health outcome is important when it comes to interpreting outcomes data [20]. It has to be identified what exactly leads to the result that is measured. Clinical expertise is needed for adequate interpretation, though what the expected outcomes are, is not always known [17].

Finally, when developing indicators one should consider that healthcare systems differ per country or state [19]. Indicators should fit in the care system they apply to. In the Netherlands for example, some DS specific initiatives have been developed. However, specialised care for adults with DS is still scarce [7]. Structural indicators may help in the development of this care, by defining what structural components of care are needed.

To conclude, quality indicators for medical DS care should focus on outcomes, with the above considerations advocating the additional use of some process and structure indicators.

\section{Strengths and limitations}

To our knowledge, this is the first review that searched for studies on quality indicators in DS care. With the use of six different databases, we covered a wide range of scientific publications. Moreover, this review discusses strategies for future development of indicators. The study contributes to existing knowledge on DS care as well as on measuring quality of care for other chronic conditions. A strength of the study is the consultation of relevant stakeholders as a last step of the review, which enabled us to check whether we had missed relevant studies or indicator sets. The fact that no additional indicator sets or studies came up in the stakeholder consultation, shows that we did not miss studies and advocates the quality of this review. Additionally, all stakeholders considered development of quality indicators for care for people with DS relevant, which also indicates the relevance of this study.

This study yielded no indicator sets on medical DS healthcare and the found indicator sets for ID healthcare predominantly focus on non-medical care (e.g. supportive care). This may be the result of including (synonyms for) intellectual disabilities as a search term, which may have put an emphasis on cognitive disability, which is not necessarily related to medical care. Using search terms on for example congenital abnormality or genetic defects might have possibly yielded more medical studies. However, these studies might have been too general and less applicable to DS. As ID is one of the outcomes of DS, we chose to search for studies on ID.

A limitation of the study was that the information of the identified indicator sets was somewhat incomplete. We only searched for information through the internet. Due to this incomplete information, not all items of the AIRE instrument, used to assess the quality, could be 
scored by the reviewers. Therefore, the low AIRE scores, especially regarding the evidence base of the sets, do not necessarily mean that the evidence base of the sets is not good. The low scores may also be a result of little available information on the sets. Consulting organisations that had developed the indicator sets might have yielded more information. However, the number of items with missing information is small and without the AIREscores, we are still able to show information on quality (development, implementation, quality domains).

\section{Conclusions}

This review gives an overview of different strategies for quality measurement. Quality indicators specific for DS care have not been published to date and in the found studies about the care for people with ID medical aspects are barely addressed. Quality indicators can play a major role in improving medical practice and evaluating whether innovations are successful. This is particularly interesting for the evolving DS care, as well as care for people with ID. As illustrated in this review, it is very hard to focus on specific care quality aspects, when approaching such a diverse, large group as 'people with intellectual disabilities'. Therefore, we recommend focussing on well-defined, DS-specific care chains when developing indicators. Further research activities should include the preparation and development of a compact set of indicators to evaluate and monitor the quality of the DS care chain as a whole. Future indicators should preferably be patient-centred and outcome-oriented, including user perspectives. In order to achieve successful implementation, it is crucial that all care providers support the indicator set, and that all care providers, patients (and/or their parents), and healthcare managers are involved in the process of development.

\section{Additional file}

Additional file 1: Overview of indicator sets with indicators. (DOCX $57 \mathrm{~kb}$ )

\begin{abstract}
Abbreviations
ACSC: Ambulatory Care Sensitive Conditions; AIRE: Appraisal of Indicators Through Research and Evaluation; DS: Down syndrome; HEDIS: Healthcare Effectiveness Data and Information Set ${ }^{\oplus}$; HEF: Health Equalities Framework; ID: Intellectual disabilities; MPOC: Measurement of Processes Of Care; NCI: National Core Indicators; NHS-QIS: National Health Services - Quality Improvement Scotland; QOF: Quality and Outcomes Framework (Indicators for learning disabilities); WHO: World Health Organisation
\end{abstract}

\section{Acknowledgements}

We would like to thank the stakeholders for checking and reviewing the identified studies and indicator sets.

\section{Funding}

This review was funded by a research grant from the Jeroen Bosch Hospital, 's-Hertogenbosch, the Netherlands, and the Nuts Ohra Foundation, the Netherlands. Both funders did not have a role in the design of the study nor in collection, analysis and interpretation of the data, nor in writing the manuscript.

\section{Availability of data and materials}

The datasets supporting the conclusions of this article are included within the article (and its Additional file 1).

\section{Authors' contributions}

FDM and MH designed the study, searched literature, collected, extracted and interpreted data and drafted the manuscript. DD, AC and EV contributed to the study design, supervised data extraction and interpretation, and critically reviewed, revised and edited the manuscript. All authors agreed to be accountable for all aspects of the work and read and approved the final version of the manuscript for publication.

\section{Competing interests}

The authors declare that they have no competing interests.

\section{Consent for publication}

Not applicable.

\section{Ethics approval and consent to participate}

Not applicable.

\section{Publisher's Note}

Springer Nature remains neutral with regard to jurisdictional claims in published maps and institutional affiliations.

\section{Author details}

${ }^{1}$ Tranzo, Scientific Center for Care and Welfare, Faculty of Social and Behavioural Sciences, Tilburg University, PO Box 90153 (T-329), 5000 LE Tilburg, The Netherlands. ${ }^{2}$ Department of Paediatrics, Jeroen Bosch Hospital, 's-Hertogenbosch, The Netherlands. ${ }^{3}$ Dichterbij, Center for the Intellectually Disabled, Gennep, The Netherlands. ${ }^{4}$ Department for Primary and Community Care, Radboud University Medical Center, Nijmegen, The Netherlands. ${ }^{5}$ Institute for Health Care Quality, National Health Care Institute, Diemen, The Netherlands. 'Severinus, Centre for the Intellectually Disabled, Veldhoven, The Netherlands.

Received: 14 February 2016 Accepted: 4 April 2017

Published online: 18 April 2017

\section{References}

1. Roizen NJ, Patterson D. Down's syndrome. Lancet. 2003;361(9365):1281-9.

2. van Gameren-Oosterom H, Buitendijk S, Bilardo C, Pal-de Bruin K, Van Wouwe J, Mohangoo A. Unchanged prevalence of Down syndrome in the Netherlands: results from an 11-year nationwide birth cohort. Prenat Diagn. 2012;32(11):1035-40

3. Weijerman ME, De Winter JP. Clinical practice. Eur J Pediatr. 2010;169(12):1445-52

4. Phelps RA, Pinter JD, Lollar DJ, Medlen JG, Bethell CD. Health care needs of children with Down syndrome and impact of health system performance on children and their families. J Dev Behav Pediatr. 2012;33(3):214-20.

5. Wexler ID, Abu-Libdeh A, Kastiel Y, Nimrodi A, Kerem E, Tenenbaum A. Optimizing health care for individuals with Down syndrome in Israel. Isr Med Assoc J. 2009;11(11):655-9.

6. Skotko BG, Davidson EJ, Weintraub GS. Contributions of a specialty clinic for children and adolescents with Down syndrome. Am J Med Genet A. 2013:161a(3):430-7.

7. de Goor R. Broodnodige zorg [indispensable care]. In: Down + Up. vol. 96. Meppel: Stichting Down Syndroom [Dutch Down syndrome foundation]. 2011. p. 34-6.

8. Jensen K, Davis M. Health care in adults with Down syndrome: a longitudinal cohort study. J Intellectual Disabil Res. 2013:57(10):947-58.

9. Bull MJ. Health supervision for children with Down syndrome. Pediatrics. 2011;128(2):393-406

10. Werkgroep Downsyndroom [Working group Down syndrome]. Update van de multidisciplinaire richtlijn voor de medische begeleiding van kinderen met Downsyndroom [update of the multidisciplinairy guideline for medical care for children with Down syndrome]. Leiden: TNO, innovation for life: 2011. 
11. Robertson J, Hatton C, Emerson E, Baines S. The impact of health checks for people with intellectual disabilities: an updated systematic review of evidence. Res Dev Disabil. 2014;35(10):2450-62.

12. Robertson J, Roberts H, Emerson E, Turner S, Greig R. The impact of health checks for people with intellectual disabilities: a systematic review of evidence. J Intellectual Disabil Res. 2011;55(11):1009-19.

13. Jensen KM, Taylor LC, Davis MM. Primary care for adults with Down syndrome: adherence to preventive healthcare recommendations. J Intellectual Disabil Res. 2013;57(5):409-21.

14. Lavigne J, Sharr C, Ozonoff A, Prock LA, Baumer N, Brasington C, Cannon S, Crissman B, Davidson E, Florez JC. National down syndrome patient database: Insights from the development of a multi-center registry study. Am J Med Genet A. 2015;167(11):2520-6.

15. Boulkedid R, Abdoul H, Loustau M, Sibony O, Alberti C. Using and reporting the Delphi method for selecting healthcare quality indicators: a systematic review. PLoS One. 2011;6(6):e20476.

16. Chen AY, Schrager SM, Mangione-Smith R. Quality Measures for Primary Care of Complex Pediatric Patients. Pediatrics. 2012;129(3):433.

17. Donabedian A. Evaluating the quality of medical care. 1966. Milbank Q. 2005;83(4):691-729.

18. Walsh KK, Kastner TA. Quality of health care for people with developmental disabilities: the challenge of managed care. Ment Retard. 1999;37(1):1-15.

19. Campbell SM, Roland MO, Buetow SA. Defining quality of care. Soc Sci Med. 2000;51(11):1611-25

20. Mainz J. Defining and classifying clinical indicators for quality improvement. Int J Qual Health Care. 2003;15(6):523-30.

21. Blumenthal D. Quality of care — what is it? N Engl J Med. 1996;335(12):891-4.

22. Campbell M, Martin M. Reducing health inequalities in Scotland: the involvement of people with learning disabilities as national health service reviewers. Br J Learn Disabil. 2010;38(1):49-58.

23. Porter ME. What is value in health care? N Engl J Med. 2010;363(26):2477-81.

24. Rademakers J, Delnoij D, de Boer D. Structure, process or outcome: which contributes most to patients' overall assessment of healthcare quality? BM Qual Saf. 2011;20(4):326-31.

25. World Health Organization. Quality of care: a process for making strategic choices in health systems. Geneva: World Health Organisation; 2006.

26. Barelds A, van de Goor I, van Heck G, Schols J. Quality of care and service trajectories for people with intellectual disabilities: defining the aspects of quality from the client's perspective. Scand J Caring Sci. 2010;24(1):164-74.

27. de Koning J, Smulders A, Klazinga N. Appraisal of Indicators through Research and Evaluation (AIRE). Versie 1.0. Utrecht: Orde van Medisch Specialisten; 2006.

28. de Bruin-Kooistra M, Amelink-Verburg MP, Buitendijk SE, Westert GP. Finding the right indicators for assessing quality midwifery care. Int J Qual Health Care. 2012;1-10.

29. Arksey H, O'Malley L. Scoping studies: towards a methodological framework. Int J Soc Res Meth. 2005;8(1):19-32.

30. Levac D, Colquhoun H, O'Brien KK. Scoping studies: advancing the methodology. Implement Sci. 2010;5(1):1-9.

31. Victoor A, Delnoij DM, Friele RD, Rademakers JJ. Determinants of patient choice of healthcare providers: a scoping review. BMC Health Serv Res. 2012;12(1):272.

32. Henderson A, Lynch SA, Wilkinson S, Hunter M. Adults with Down's syndrome: the prevalence of complications and health care in the community. Br J Gen Pract. 2007:57(534):50-5.

33. Alonazi WB, Thomas SA. Quality of Care and Quality of Life: Convergence or Divergence? Health Serv Insights. 2014. doi:10.4137/HSI.S13283(7):1-12.

34. van Loon JH, Bonham GS, Peterson DD, Schalock RL, Claes C, Decramer AE. The use of evidence-based outcomes in systems and organizations providing services and supports to persons with intellectual disability. Eval Program Plann. 2013;36(1):80-7.

35. Wiering BM, Noordman J, Tates K, Zwaanswijk M, Elwyn G, De Bont ES, Beishuizen A, Hoogerbrugge PM, Van Dulmen S. Sharing decisions during diagnostic consultations; an observational study in pediatric oncology. Patient Educ Couns. 2016;99(1):61-7.

36. Campbell SM, Hann M, Roland MO, Quayle JA, Shekelle PG. The effect of panel membership and feedback on ratings in a two-round Delphi survey: results of a randomized controlled trial. Med Care. 1999:37(9):964-8.

37. Flood B, Henman M. Building quality indicators for medication use in people aging with intellectual disabilities and behaviour disorders. Int J Dev Disabil. 2014, doi:2047387714Y.0000000061.
38. Callaghan L. The use of collaboration in personal outcomes. Int J Health Care Qual Assur. 2006;19(5):384-99.

39. Balogh R, Brownell M, Ouellette-Kuntz H, Colantonio A. Hospitalisation rates for ambulatory care sensitive conditions for persons with and without an intellectual disability-a population perspective. J Intellectual Disabil Res. 2010;54(9):820-32.

40. Balogh RS, Ouellette-Kuntz H, Brownell M, Colantonio A. Ambulatory Care Sensitive Conditions in Persons with an Intellectual Disability - Development of a Consensus. J Appl Res Intelect Disabil. 2011;24(2):150-8.

41. Glover G, Evison F. Hospital Admissions That Should Not Happen. Lancaster: Improving Health and Lives: Learning Disabilities Observatory; 2013.

42. Shireman TI, Reichard A, Nazir N, Backes JM, Greiner KA. Quality of diabetes care for adults with developmental disabilities. Disabil Health J. 2010;3(3):179-85.

43. HEDIS ${ }^{\oplus}$ Measure Development Process. https://www.ncqa.org/Portals/0/ HEDISQM/Measure_Development.pdf. (year unknown). Accessed 22 July 2015.

44. HEDIS ${ }^{\circledR}$ Measures. http://www.ncqa.org/HEDISQualityMeasurement/ HEDISMeasures.aspx. (year unknown). Accessed 20 July 2015.

45. Thomas B. Improving care for people with learning disabilities. Nurs Stand. 2014;28(21):31.

46. Atkinson D, Boulter P, Hebron C, Moulster G, Giraud-Saunders A, Turner S. The Health Equalities Framework (HEF) An outcomes framework based on the determinants of health inequalities. Bath: National Develpment Team for Inclusion, Improving Health and Lives: Learning Disabilities Observatory, UK Learning Disability Consultant Nurse Network; 2013.

47. Granat T, Lagander B, Borjesson MC. Parental participation in the habilitation process - Evaluation from a user perspective. Child Care Health Dev. 2002;28(6):459-67.

48. Cunningham BJ, Rosenbaum PL. Measure of processes of care: a review of 20 years of research. Dev Med Child Neurol. 2014;56(5):445-52.

49. Bradley VJ, Moseley C. National core indicators: Ten years of collaborative performance measurement. Intellect Dev Disabil. 2007;45(5):354-8.

50. National Core Indicators ${ }^{\mathrm{TM}}$. 2015. http://www.nationalcoreindicators.org/. Accessed 16 July 2015

51. About National Core Indicators. 2015. http://www.nationalcoreindicators. org/about/. Accessed 16 July 2015.

52. NHS Quality Improvement Scotland. Quality Indicators Learning Disabilities. Edinburgh: NHS Quality Improvement Scotland; 2004.

53. NHS Quality Improvement Scotland. National Overview Learning Disability Services. Edinburgh: NHS Quality Improvement Scotland; 2006.

54. Campbell M. The importance of good quality services for people with complex health needs. Br J Learn Disabil. 2008;36(1):32-7.

55. POMONA II Research group. POMONA II: Gezondheidswijzer voor mensen met verstandelijke beperkingen. [POMONA II: health guideline for people with intellectual disabilities]. In: Een indicatorset gebruiken [Using an indicator]. Edited by Project 2004130 European Commission: Directorate C Public health and risk assessment: POMONA II; 2006.

56. van Schrojenstein Lantman-de Valk H, Linehan C, Kerr M, Noonan-Walsh P. Developing health indicators for people with intellectual disabilities. The method of the Pomona project. J Intellectual Disabil Res. 2007;51(6):427-34.

57. Coker TR, Shaikh Y, Chung PJ. Parent-reported quality of preventive care for children at-risk for developmental delay. Acad Pediatr. 2012;12(5):384-90.

58. Blumberg SJ, Foster EB, Skalland BJ, Chowdhury SR, O'Connor KS. Design and Operation of the National Survey of Children's Health, 2007. Hyattsville: National Center for Health Statistics, Department of Health and Human Services, Centers for Disease Control and Prevention; 2007.

59. Data Resource Center for Child \& Adolescent Health. National Survey of Children's Health (NSCH). In: Guide to Topics \& Questions Asked. 2007.

60. Taggart L, Coates V, Truesdale-Kennedy M. Management and quality indicators of diabetes mellitus in people with intellectual disabilities. $J$ Intellectual Disabil Res. 2013;57(12):1152-63.

61. Diabetes UK. Diabetes 15 Healthcare Essentials. London: Diabetes UK; 2014.

62. Spears AP. The Healthy People 2010 outcomes for the care of children with special health care needs: an effective national policy for meeting mental health care needs? Matern Child Health J. 2010;14(3):401-11.

63. Blumberg SJ, Welch EM, Chowdhury SR, Upchurch HL, Parker EK, Skalland BJ. Design and Operation of the National Survey of Children with Special Health Care Needs, 2005-2006. Washington DC: National Center for Health Statistics. Vital and Health Statistics; 2008.

64. Data Resource Center for Child \& Adolescent Health. Guide to Topics \& Questions Asked. In: National Survey of Children with Special Health Care Needs (NS-CSHCN), 2009-2010. 2009. 
65. Strickland BB, van Dyck PC, Kogan MD, Lauver C, Blumberg SJ, Bethell CD, Newacheck PW. Assessing and ensuring a comprehensive system of services for children with special health care needs: a public health approach. Am J Public Health. 2011:101(2):224-31.

66. U.S. Department of Health and Human Services, Health Resources and Services Administration, Maternal and Child Health Bureau. The National Survey of Children with Special Health Care Needs Chartbook 2005-2006. Rockville: U.S. Department of Health and Human Services; 2007.

67. Ashworth M. The Quality and Outcomes Framework in the United Kingdom: Indicators in Transition. J Ambul Care Manage. 2012;35(3):200-5.

68. National Institute for Health and Clinical Excellence. Quality and Outcomes Framework (QOF) Indicator Development Programme Briefing paper. London: National Institute for Health and Clinical Excellence; 2009.

69. National Institute for Health and Clinical Excellence. Primary Care Quality and Outcomes Framework Indicator Advisory Committee recommendations. London: National Institute for Health and Clinical Excellence; 2010.

70. National Institute for Health and Clinical Excellence. Quality and Outcomes Framework (QOF) Indicator Development Programme Draft QOF indicator guidance. London: National Institute for Health and Clinical Excellence; 2013.

71. National Institute for Health and Clinical Excellence. Learning Disabilities. 2016. https://www.nice.org.uk/standards-and-indicators/ qofindicators?categories=3901\&page=1. Accessed 4 Jan 2016.

72. National Institute For Health and Clinical Excellence. Standards and Indicators. 2016. http://www.nice.org.uk/standards-and-indicators. Accessed 4 Jan 2016.

73. National Institute for Health and Clinical Excellence. How we develop the NICE Indicator Menu for the QOF. 2016. http://www.nice.org.uk/standardsand-indicators/How-we-develop-QOF. Accessed 4 Jan 2016

74. Flood B, Henman MC. Case study: hidden complexity of medicines use: information provided by a person with intellectual disability and diabetes to a pharmacist. Br J Learn Disabil. 2015. doi:10.1111/bld.12121.

\section{Submit your next manuscript to BioMed Central} and we will help you at every step:

- We accept pre-submission inquiries

- Our selector tool helps you to find the most relevant journal

- We provide round the clock customer support

- Convenient online submission

- Thorough peer review

- Inclusion in PubMed and all major indexing services

- Maximum visibility for your research

Submit your manuscript at www.biomedcentral.com/submit
Biomed Central 